\title{
A real-time RT-PCR for rapid detection and quantification of mosquito-borne alphaviruses
}

\author{
Marilia Farignoli Romeiro ${ }^{1}$ - William Marciel de Souza ${ }^{1}$ - Aline Lavado Tolardo ${ }^{1}$.

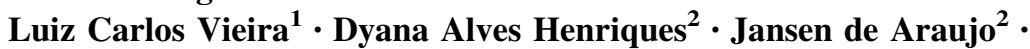 \\ Carlos Eduardo Hassegawa Siqueira ${ }^{3}$ - Tatiana Elias Colombo ${ }^{5}$ - Victor Hugo Aquino ${ }^{4}$. \\ Benedito Antonio Lopes da Fonseca ${ }^{1}$. Roberta Vieira de Morais Bronzoni ${ }^{3}$. \\ Maurício Lacerda Nogueira ${ }^{5}$ Edison Luiz Durigon ${ }^{2} \cdot$ Luiz Tadeu Moraes Figueiredo $^{1}$
}

Received: 18 December 2015/Accepted: 16 August 2016/Published online: 24 August 2016

(c) Springer-Verlag Wien 2016

\begin{abstract}
Mosquito-borne alphaviruses are widely distributed throughout the world, causing important human illnesses. Therefore, the development of methods to enable early diagnosis of infections by alphavirus is essential. We show here the development and evaluation of a quantitative real-time RT-PCR using genus-specific primers to the nsP1 viral gene of all mosquito-borne alphaviruses. The specificity and sensitivity of the assay were tested using seven alphaviruses and RNA transcribed from Venezuelan equine encephalitis virus. The detection limits of real-time RTPCR ranged from 10 to 76 copies per $\mathrm{ml}$. The melting temperature $\left(\mathrm{T}_{\mathrm{M}}\right)$ values for amplification of the alphavirus genomes were $83.05^{\circ} \mathrm{C}$ and $85.28^{\circ} \mathrm{C}$. Interestingly, the assay suggested the possibility the arthritogenic
\end{abstract}

Marilia Farignoli Romeiro

mafarignoli@hotmail.com

Luiz Tadeu Moraes Figueiredo

ltmfigue@fmrp.usp.br

1 Virology Research Center, School of Medicine of Ribeirao Preto of University of Sao Paulo, Av. Bandeirantes, 3900, Ribeirão Preto, São Paulo 14049-900, Brazil

2 Laboratório de Virologia Clínica e Molecular, Instituto de Ciências Biomédicas, Universidade de São Paulo, São Paulo, Brazil

3 Instituto de Ciências da Saúde, Centro Universitário de Sinop, Universidade Federal de Mato Grosso Mato Grosso, Sinop, Mato Grosso, Brazil

4 Laboratório de Virologia, Departamento de Análises Clínicas, Toxicológicas e Bromatológicas, Faculdade de Ciências Farmacêuticas de Ribeirão Preto, Universidade de São Paulo, Ribeirão Preto, São Paulo, Brazil

5 Laboratório de Pesquisa em Virologia, Faculdade de Medicina de São José do Rio Preto, São José do Rio Preto, São Paulo, Brazil alphaviruses with $\mathrm{T}_{\mathrm{M}}$ peaks of 84.83 to $85.28{ }^{\circ} \mathrm{C}$ and encephalitic alphaviruses of $83.34{ }^{\circ} \mathrm{C}$ to $84.68{ }^{\circ} \mathrm{C}$ could be discriminated both diseases. Real-time RT-PCR may prove very useful for the screening and preliminary diagnosis in outbreaks and surveillance studies as well as for measuring the viral load in pathogenesis studies.

\section{Introduction}

Viruses of the Alphavirus genus, Togaviridae family, are enveloped and have a positive-sense, single-stranded RNA genome. The genome is approximately 12 kilobases, and encodes four nonstructural proteins (nsP1 to nsP4) and five structural proteins (C, E3, E2, 6K, and E1) [24, 33]. Alphaviruses are found on all continents, and the 28 known species are included in at least seven antigenic complexes, which can be differentiated by serological tests, particularly neutralization assays [24, 30].

In nature, alphaviruses are maintained in complex cycles involving arthropod vectors and vertebrate reservoirs (arbovirus). The most important vectors involved in the transmission of these viruses are Culex and Aedes mosquitoes, and their vertebrate hosts are mammals, birds, and eventually, humans [36].

Human infection by the alphaviruses of Semliki Forest group, including the Semliki Forest virus (SFV), Chikungunya virus (CHIKV), Ross River virus (RRV), Barmah Forest virus (BFV), O'nyong-nyong virus (ONNV) and Mayaro virus (MAYV), produce acute febrile illnesses associated with joint pain and, in some cases, arthritis that can become chronic and debilitating [18, 31, 34]. In the last 10 years, CHIKV has produced massive outbreaks in several countries of Asia, islands in the Indian and Pacific Oceans, Africa and Europe [17, 21]. In 2013, CHIKV was 
introduced in the Americas, producing epidemics. In the Caribbean, CHIKV was responsible for 700,000 to 1.3 million infections in 45 countries or territories [17, 21, 29]. In 2014, Brazil suffered two introductions of CHIKV, one by the Asian strain in the North and another by the East, Central and South African strain in the Northeast [5]. Additionally, numerous alphaviruses, such as the Eastern equine encephalitis (EEEV), Western Equine Encephalitis (WEEV) and Venezuelan Equine encephalitis have produced many epizootics in ungulates and epidemics in human populations of the Americas [13, 36]. EEEV, VEEV and WEEV are known to cause human and equine encephalomyelitis with high fatality rates and the development of neurological sequelae in survivors [38].

Presently, alphaviruses are an important public health problem in the Americas [17, 20, 29, 34, 38]. These viruses have been introduced into new areas as a consequence of the rapid expansion of international travel. Furthermore, ecological disturbances produced by man have resulted in an imbalance of sylvatic cycles bringing vectors and consequently, the alphaviruses closer to urban areas [36]. Consequentially, the wide variety of reservoirs coupled with the spreading of both vectors and viruses through international travel has led to the global distribution of these viruses. Moreover, the lack of effective antiviral treatments or human vaccines have enabled alphaviruses to become a threat that can result in explosive epidemics, as recently described for CHIKV in the Americas [5, 20, 36].

In this context, the diagnosis of alphavirus infection is critical. In the past, the diagnosis of infection by alphavirus has been performed by virus isolation or by serological assays [17, 22]. Presently, this diagnosis is performed by serology using enzyme-linked immunosorbent assays (ELISA) and RT-PCR (reverse transcription-polymerase chain reaction) using species-specific primers to some alphaviruses [1, 12, 19, 22, 25]. An early and accurate diagnosis of alphavirus infections is necessary for the management of patients and the adoption of efficient preventive measures [1, 17, 22]. Herein, we describe a SYBR Green I real-time RT-PCR for the detection and quantification of all mosquito-borne alphaviruses.

\section{Material and methods}

\section{Alphavirus, RNA extraction and cDNA synthesis}

The alphaviruses used for evaluation of the real-time RT-PCR were propagated in C6/36 Aedes albopictus cells cultured in Leibovitz's L-15 medium supplemented with $10 \%$ heat-inactivated fetal bovine serum, $50 \mathrm{mg} / \mathrm{ml}$ of gentamicin and $2 \mathrm{mg} / \mathrm{ml}$ of amphotericin B (Vitrocell, Brazil). The infected cells were incubated for three days at $28{ }^{\circ} \mathrm{C}$. Cell infection with alphavirus was confirmed by an indirect immunofluorescent test, as previously described [6]. The culture medium of infected cells was centrifuged, and the supernatant was aliquoted as viral stock and stored at $-80^{\circ} \mathrm{C}$. Viral RNA was extracted using the QIAamp viral RNA extraction kit (Qiagen, Germany) and the viral RNA from alphavirus was converted to double-stranded cDNA using Superscript III (Invitrogen, USA), both according to the manufacturer's instructions.

\section{Real-time RT-PCR and primers}

To develop the real-time PCR, the KAPA SYBR FAST Universal 2X qPCR Master Mix (Kapa Biosystems, USA) was used. We used primers that are alphavirus genusspecific as previously reported [22]. All reactions were carried out in a StepOnePlus ${ }^{\mathrm{TM}}$ Real-Time PCR System (Applied Biosystems, USA).

\section{Standard curve, limit of detection and specificity of real-time RT-PCR}

To enable quantitation in real-time RT-PCR, we introduced a fragment of 434 nucleotides of the nsP1 gene of VEEV strain TC-83 into the pET28a vector and then transformed the resulting clone into Escherichia coli DH5 $\alpha$ cells (Invitrogen, USA), according to the manufacturer's protocol. The nsP1 insertion was confirmed by PCR as previously reported [3]. Subsequently, we did perform PCR against the T7 region of the pET28a-nsP1 vector, using a forward primer containing the $\mathrm{T} 7$ promoter region (5'-TAATACGACTCACTATAGGG- $3^{\prime}$ ) and a reverse primer containing the $\mathrm{T} 7$ terminator region (5'-GCTAGTTATTGCTCAGCGG-3'), using Taq DNA polymerase (Invitrogen, USA) as recommended by the manufacturer. Following an initial denaturation at $94{ }^{\circ} \mathrm{C}$ for $3 \mathrm{~min}$, amplification was performed in 45 cycles of $94{ }^{\circ} \mathrm{C}$ for 45 sec for denaturation, $58{ }^{\circ} \mathrm{C}$ for $30 \mathrm{sec}$ for annealing, and $72{ }^{\circ} \mathrm{C}$ for $90 \mathrm{sec}$ for extension, with a final extension at $72{ }^{\circ} \mathrm{C}$ for $5 \mathrm{~min}$. The amplicon was purified using the QIAquick PCR Purification Kit (Qiagen, Germany). The in vitro transcription of the purified amplicon was performed using the MEGAscript T7 Transcription Kit (Invitrogen, USA). The reaction product containing the transcribed RNA of VEEV was treated with $1 \mathrm{U}$ of Turbo DNAse (Ambion, USA), purified using the RNeasy kit (Qiagen, Germany), and quantified with the Qubit 2.0 Fluorometer (Invitrogen, USA) and stored at $-80^{\circ} \mathrm{C}$. The concentration of the transcribed RNA was transformed into RNA copies/ml using the following formula: RNA copy number $($ copies $/ \mathrm{ml})=$ RNA concentration $(\mathrm{g} / \mathrm{ml}) /$ length of the transcript $\times 340 \times 6.022 \times 10^{23}$. 
The standard curve for quantitation of RNA alphavirus in the real-time RT-PCR was performed with five serial dilutions of the transcribed RNA from VEEV, as described above. The viral load was determined based on the standard curve obtained from $\mathrm{Ct}$ values of the serial dilutions of the transcribed RNA from VEEV. Four independent runs, including three replicates of each serial dilution of the transcribed RNA, were performed to obtain the standard curve.

The limit of detection of the real-time RT-PCR for alphavirus was determined using triplicates of the serial dilutions of in vitro transcribed RNA from VEEV $\left(6.42 \times 10^{11}\right.$ to $6.42 \times 10^{-1}$ RNA copies per ml $)$ and as serial dilutions of each alphavirus tested. The specificity of real-time RT-PCR for alphavirus was checked with other viruses, including, the Flavivirus, Dengue 1 virus strain Mochizuki, Dengue 2 virus strain New Guinea C, Dengue 3 virus strain H-87, Dengue 4 virus strain H-241, Zika virus (isolated from patient with febrile acute disease in Ceará State, Brazil), Rocio virus strain SPH 34675, Ilheus virus strain BeH 7445. Also was used the Orthobunyavirus, Oropouche strain BeAn1999. The Vesiculovirus Piry virus strain BeAn 41191, Citomegalovirus strain AD169 (Herpesviridae), Adenovirus, isolated from patient in Ribeirao Preto, Brazil, (Adenoviridae), Respiratory Syncytial virus type A strain long (Paramyxoviridae) and the Rinovirus type A strain HRV16 (Picornaviridae).

\section{Analysis of the amplicon obtained with the genus- specific primers}

Sequences of the nsP1 genes of alphaviruses were retrieved from GenBank to assess characteristics of products potentially amplified by the $\mathrm{M} 2 \mathrm{~W}$ and $\mathrm{cM} 3 \mathrm{~W}$ primers [22]. These sequences included VEEV (GenBank accession numbers KC344516, KC344517, KC344512, KC344519, KC344525, KC344521, KC344518, AF075251), WEEV (NC_003908, AF214040, GQ287645, GQ287643, KJ554985, KJ554984, GQ287644, GQ287647, KJ554983, KJ554981, GQ287642, GQ287641, KJ554991, KJ554990, KJ554989, KJ554988, KJ554986, KJ554982, GQ287640, GQ287646), EEEV (NC_003899, AY722102, KJ659366, KJ659351, KJ659346, KJ659347, KJ659344, AY705241, KJ469650, KJ469649), Aura virus (AF126284, NC_003900), CHKV (EF210157, JF274082, N558836, JX088705, AF369024, KJ013266) and MAYV (DQ001069, NC003417, AF237947). The sequences were aligned using MAFFT v7.158b [11] and the predicted amplification fragments, flanked by the putative annealing sites of M2W and cM3W primers (nucleotide positions 154 to 598) were selected to determine GC content (\%) using the Geneious v.8.0.1 program.

\section{Clinical samples}

To evaluate the clinical applicability of our assay, the sera of 410 patients presenting acute febrile illness but negative for Dengue in laboratory tests were analyzed. Of those samples, 88 were obtained from patients between 2011 and 2013, during an outbreak of Dengue in Sao Jose do Rio Preto and 155 samples during an outbreak of Dengue between 2006 and 2008 in Ribeirao Preto; both are cities in Sao Paulo State, Brazil. The remaining 167 samples, from suspected Dengue patients, were obtained in 2011 in Sinop City, Mato Grosso State, Brazil. Furthermore, the serum samples from two patients with CHIKV infection, one from Sao Jose do Rio Preto and another from Ribeirao Preto, were tested. This study was approved by the Human Research Ethics Committee of the School of Medicine of Ribeirao Preto, University of Sao Paulo, Brazil (Process No. 2013/164.277).

\section{Results}

To develop our assay, we successfully cloned the partial nsP1 gene of VEEV into the pET28a vector, introduced the clone into Escherichia coli and performed in vitro transcription to generate an RNA fragment for use as a standard control in our assay. This standard had an initial concentration of $249 \mathrm{ng}$ per $\mathrm{ml}$ and contained $6.42 \times 10^{11}$ RNA copies per ml. To develop the real-time RT-PCR, the KAPA SYBR FAST Universal 2X qPCR Master Mix (Kapa Biosystems, USA) was used with the reaction mixture containing $2 \mu \mathrm{l}$ of cDNA template, $2 \mu \mathrm{l}$ of each primer (M2W forward and cM3W reverse at 10 pmol per $\mu \mathrm{l}$ ), 0.4 $\mu \mathrm{l}$ of ROX buffer (2X), $10 \mu \mathrm{l}$ of SYBR buffer (2X), and 3.6 $\mu \mathrm{l}$ of DEPC water in a final volume of $20 \mu$ l. The optimal cycling conditions were $95{ }^{\circ} \mathrm{C}$ for $10 \mathrm{~min}$ followed by 45 cycles at $95^{\circ} \mathrm{C}$ for $15 \mathrm{sec}$ and $60{ }^{\circ} \mathrm{C}$ for $1 \mathrm{~min}$.

The equivalent $\Delta \mathrm{Rn}$ amplification plot curves were obtained when testing serial dilutions of the alphavirus transcribed RNA from VEEV in triplicate with a threshold value of 0.055305 . Serial dilutions of the alphavirus standard RNA were tested, and their $\mathrm{C}_{\mathrm{T}}$ values were plotted to generate the standard curve for the reaction. The standard curve parameters obtained from the SYBR Green I realtime quantitative RT-PCR were as follows: a slope of -3.457 , a percent efficiency (EFF) of $94.64 \%$, a correlation coefficient $\left(\mathrm{R}_{2}\right)$ of 0.801 and a Y-intercept of 43.481 (Figure 1).

The $\mathrm{C}_{\mathrm{T}}$ values obtained from transcribed RNA of VEEV dilutions were reproducible. The $\mathrm{T}_{\mathrm{M}}$ peak between $83.05{ }^{\circ} \mathrm{C}$ and $83.64{ }^{\circ} \mathrm{C}$ was observed with in vitro transcribed RNA based VEEV, as shown by the melting curves in Figure 1. The $T_{M}$ peaks of the negative control occurs 

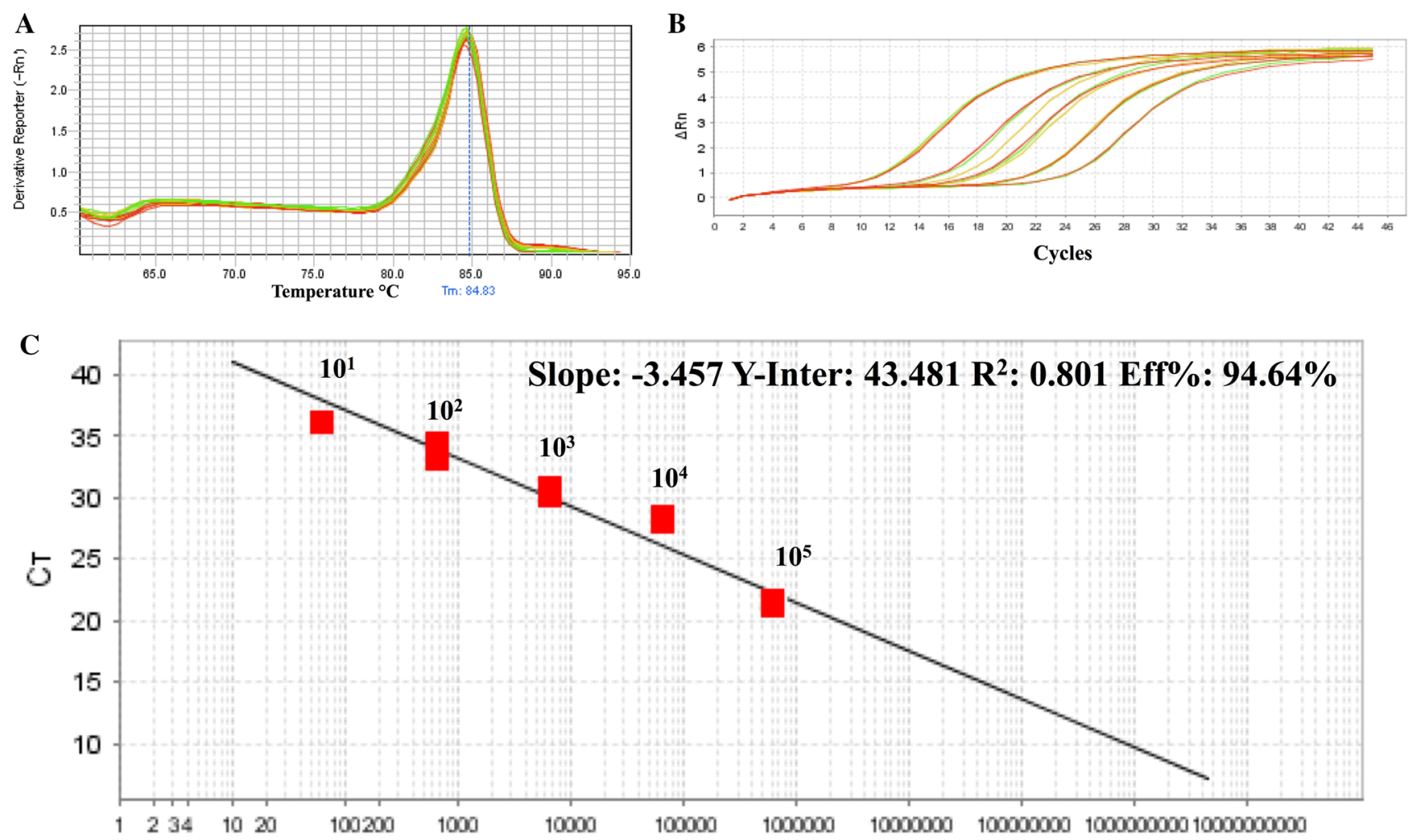

Viral load (copies of RNA per ml)

Fig. 1 Standard curve of real-time RT-PCR with in vitro transcribed RNA of Venezuelan equine encephalitis. (A) Melting curves of realtime RT-PCR products from serial 10-fold dilutions of the standard control RNA of Venezuelan equine encephalitis. (B) Amplification

$74.55{ }^{\circ} \mathrm{C}$ to $75.44{ }^{\circ} \mathrm{C}$, which is clearly distinguishable from the result of the positive controls. Different $\mathrm{T}_{\mathrm{M}}$ peaks were observed in the SYBR Green I real-time RT-PCR for alphaviruses, as follows: 84.83 to $85.28{ }^{\circ} \mathrm{C}$ for CHIKV and MAYV, which are both members of Semliki Forest complex. Additional distinct $\mathrm{T}_{\mathrm{M}}$ peaks from $83.34{ }^{\circ} \mathrm{C}$ to $84.68{ }^{\circ} \mathrm{C}$ were observed for the following encephalitic viruses: EEEV, VEEV, WEEV, Mucambo (MUCV) and Aura (AURV) (Figure 2 and Table 1). To assess the molecular differences that could explain these distinct $T_{M}$ peaks, a dataset of $49 \mathrm{nsP} 1$ gene sequences of alphaviruses were analyzed. The GC content between nucleotide positions 154 to 598 was $51.6 \%$ for Semliki Forest complex viruses (CHIKV and MAYV) and $49 \%$ for other alphaviruses.

The real-time RT-PCR for alphavirus showed high sensitivity, as it was able to detect 10 copies per $\mathrm{ml}$, which was determined by testing serial dilutions containing $6.42 \times 10^{11}$ to $6.42 \times 10^{-1}$ copies per $\mathrm{ml}$ of the transcribed RNA from VEEV per ml. In addition, we determined the sensitivity for each alphavirus on serial diluitions, the VEEV detected 10 copies of RNA/ml, curves obtained from serial 10-fold dilutions of the standard control RNA of Venezuelan equine encephalitis. (C) Standard curve generated using $\mathrm{C}_{\mathrm{T}}$ values from serial dilutions of the control in vitro transcribed RNA of Venezuelan equine encephalitis

WEEV detected 76 copies of RNA/ml, EEEV detected 52 copies of RNA/ml, MUCV detected 47 copies of RNA $/ \mathrm{ml}$, AURV detected 46 copies of RNA/ml, MAYV detected 10 copies of RNA/ml and CHIKV detected 10 copies of RNA/ $\mathrm{ml}$. The test displays a broad spectrum of detection because all tested alphavirus were amplified (Table 1). Additionally, serial dilutions allowed us to generate a standard curve by plotting the values of the threshold cycle $\left(\mathrm{C}_{\mathrm{T}}\right)$ relative to the copy number of the transcribed RNA from VEEV (Table 1). The real-time RT-PCR for alphavirus did not amplify the genomes of others viruses including Dengue 1, Dengue 2, Dengue 3, Dengue4, Zika, Rocio, Ilheus, Oropouche, Piry, Citomegalovirus, Adenovirus, Rinovirus and Respiratory Syncytial virus.

In the evaluation of real-time RT-PCR for detection of alphavirus, we tested serum samples from 410 patients with acute febrile illness from two different regions of Brazil, but we did not detect the genome of alphavirus. We did, however, confirm the diagnoses of two patients with CHIKV infection. The first case, a patient of Ribeirao Preto city, had $9.5 \times 10^{7}$ copies of virus RNA per ml, while the second was a patient of Sao Jose do Rio Preto city who had 

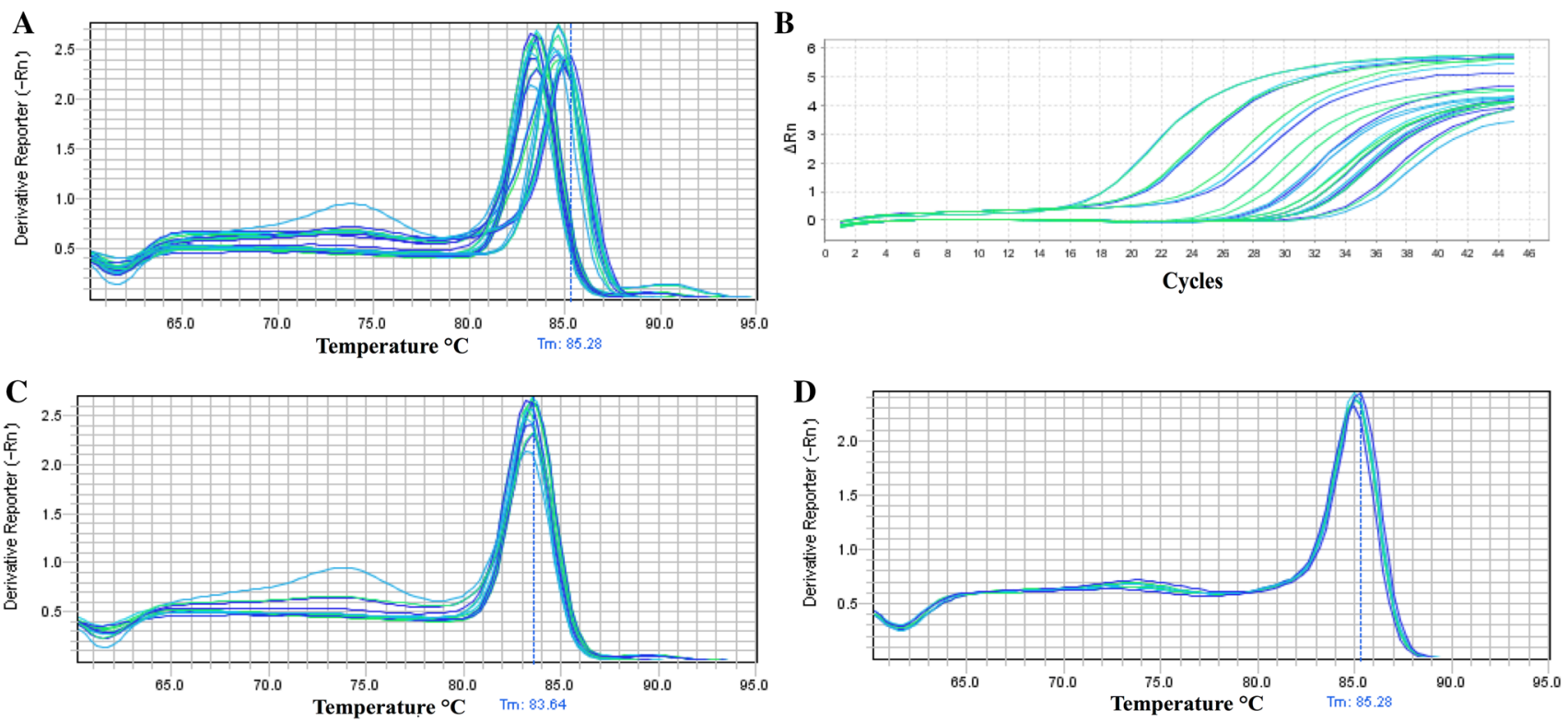

Fig. 2 Melting curve peaks and amplification curve of real time RTPCR from mosquito-borne alphavirus. (A) Melting peaks of real-time RT-PCR obtained from mosquito-borne alphaviruses described in Table 1. (B) Amplification curves obtained from mosquito-borne

alphaviruses described in Table 1. (C) Amplification curves obtained from Encephalitis alphaviruses (VEEV, EEEV, WEEV, AURV and MUCV). (D) Amplification curves obtained from arthritogenic alphaviruses (MAYV and CHIKV)

Table 1 Viruses used for the development of real time RTPCR for mosquito-borne alphaviruses

\begin{tabular}{lllll}
\hline Viral species & Strain & $\mathrm{T}_{\mathrm{M}}$ peak $\left({ }^{\circ} \mathrm{C}\right)$ & Viral load & Sensitivity limit \\
\hline VEEV & BeAr 40403 & $84.58+/-0.07$ & $6.4 \times 10^{3}$ copies of RNA/ml & 10 copies of RNA $/ \mathrm{ml}$ \\
EEEV & SpAn 14723 & $83.59+/-0.07$ & $5.2 \times 10^{7}$ copies of RNA/ml & 52 copies of RNA $/ \mathrm{ml}$ \\
WEEV & Rio 1257 & $83.39+/-0.07$ & $7.6 \times 10^{6}$ copies of RNA/ml & 76 copies of RNA $/ \mathrm{ml}$ \\
Aura & BeAr 10315 & $83.42+/-0.06$ & $4.6 \times 10^{4}$ copies of RNA $/ \mathrm{ml}$ & 46 copies of RNA $/ \mathrm{ml}$ \\
Mucambo & BeAn 8 & $83.24+/-0.07$ & $4.7 \times 10^{5}$ copies of RNA/ml & 47 copies of RNA $/ \mathrm{ml}$ \\
Mayaro & BeAr 20290 & $84.93+/-0.07$ & $3.8 \times 10^{3}$ copies of RNA $/ \mathrm{ml}$ & 10 copies of RNA $/ \mathrm{ml}$ \\
Chikungunya & S27-African & $85.28+/-0.07$ & $2.0 \times 10^{3}$ copies of RNA/ml & 10 copies of RNA $/ \mathrm{ml}$ \\
\hline
\end{tabular}

Legend: VEEV (Venezuelan Equine Encephalitis Virus), EEEV (Eastern Equine Encephalitis Virus) and WEEV (Western Equine Encephalitis Virus). $\mathrm{T}_{\mathrm{M}}$ peak (Temperature melting peak), +/- (Standard deviation), Viral load is express in copies of RNA/ml

$1.4 \times 10^{5}$ copies of RNA per ml. The CHIKV genomes detected in both sera displayed $T_{M}$ peaks compatible with those of alphaviruses of the Semliki Forest complex.

\section{Discussion}

Alphaviruses, specially VEEV, MAYV and more recently CHIKV, have caused several outbreaks in South America of high impact in human and animal public health $[5,7,15,18,20,23,32]$. Other zoonotic alphaviruses are also circulating in the area causing sporadic human diseases. Considering the importance of accurate patient diagnosis for the management of alphavirus outbreaks, here, we describe a novel assay that can be used in the diagnosis and surveillance of alphaviruses. This test is simple, fast, highly sensitive, and has a low risk of contamination.

To date, the real-time RT-PCR assays that have been reported have focused on specific species of alphavirus, and only some utilize SYBR Green technology $[8,9,26-28,37,39]$. However, an assay able to simultaneously diagnose all currently known species of mosquitoborne alphaviruses would be more useful than speciesspecific reactions. Thus, in our assay, the primers chosen anneal to a conserved region of 434 nucleotides in the gene of nsP1 of 27 species of mosquito-borne alphavirus [22]. Furthermore, due to the high conservation observed in this region, this assay can be used to detect novel alphaviruses.

In fact, the real-time RT-PCR we developed has a broad range of detection for alphaviruses; all the alphaviruses included in this study are emerging or potentially emerging 
viruses in Brazil and result in human diseases $[24,29,31,35,36]$. The genomes of the alphaviruses tested generated amplicons with melting curve values ranging from 83.34 to $85.13{ }^{\circ} \mathrm{C}$, showing the wide range and the detection potential of this assay. The advantage of the SYBR Green system is the possibility to discriminate viral species via melting curves [14]. Here, we observed two $T_{M}$ peak groups in the reaction, the first group ranging between 84.83 and $85.28{ }^{\circ} \mathrm{C}$ for CHIKV and MAYV, both members of the Semliki Forest virus complex which produce acute febrile illness with arthropathy in infected patients [31]. In contrast, the WEEV, EEEV, VEEV, which cause infections of the central nervous system, and also the Aura virus, all produced $\mathrm{T}_{\mathrm{M}}$ peaks between 83.34 and $84.68{ }^{\circ} \mathrm{C}$ [38]. These distinct ranges of the melting curves are related to differences produced by G-C bonds in the PCR product that contribute to stability, thus increasing the melting temperature with increasing GC content [16]. The Semliki Forest complex viruses have $51.6 \%$ GC content while all other alphaviruses tested contained $49 \%$ GC. Therefore, our data, in accordance with the known GC content of the viruses tested, suggest that it is possible to distinguish between these two groups of alphavirus on the basis of the $\mathrm{T}_{\mathrm{M}}$ peak produced, which could provide a rapid preliminary identification of these pathogens, before sequencing the amplicons for more accurate diagnosis.

The high sensitivity of our real-time RT-PCR to detect alphavirus was demonstrated based on the ability to detect the in vitro transcribed RNA standard at concentrations as low as 10 copies of viral RNA per ml. The viral load in alphavirus infection was shown in a study of 199 patients with CHIKV infection from India, with a mean viremia of $728 \times 10^{8}$ viral RNA copies per ml, ranging from 97.4 to $1.43 \times 10^{11}$ copies per $\mathrm{ml}$ [4]. This work indicates high levels of viremia during the acute phase of CHIKV infection that is also supposed to occur in other alphavirus infections. In our study, we validated the diagnosis of two cases of CHIKV infection, both with features of acute febrile illness and a high viral load of $1.4 \times 10^{5}$ and $9.5 \times 10^{7}$ copies per $\mathrm{ml}$. These viral loads typical of acute infection by CHKV were easily detected by the SYBR Green I real-time RT-PCR. However, we did not detect any alphavirus in the serum of patients with acute febrile illness from Southeast (Sao Paulo State) and Central-West (Mato Grosso State) Brazil, probably because the native viruses do not frequently produce disease and especially because our analyzed cases occurred before the introduction of CHIKV in Brazil [5, 20].

In short, we describe the first real-time RT-PCR with a broad specificity to alphavirus infections, compared to previously assays that primarily focused on CHIKV, EEEV, and Sindbis virus, alone or in combination with other arboviruses [2, 10, 25, 37, 39]. Therefore, our assay may be very useful for the preliminary diagnosis and screening of infections by alphaviruses, during outbreaks, and in general surveillance studies. Subsequently, the virus in positive samples could be identified by species-specific PCR assays or by direct sequencing of the amplicons. Moreover, we improved the real-time RT-PCR assay to allow quantification of the viral genome, which can be easily established for monitoring viral activity and to measure the viral load in pathogenesis studies.

\section{Compliance with ethical standards}

Funding This work was financially supported by Fundação de Amparo à Pesquisa do Estado de São Paulo (Grant No. 13/14929-1 and Scholarships No. 12/02836-6; 14/20851-8; 12/24150-9; 13/02256-2 and 14/15079-4). LTM Figueiredo is the recipient of a CNPq 1B senior fellowship (No. 301677/2013-1).

Conflict of interest The authors declare that they have no competing interests.

Ethical approval All procedures performed in studies involving human participants were in accordance with the ethical standards of the institutional and/or national research committee and with the 1964 Helsinki declaration and its later amendments or comparable ethical standards. This study was approved by the Human Research Ethics Committee of the School of Medicine of Ribeirao Preto, University of Sao Paulo, Brazil (Process No. 2013/164.277).

Informed consent Informed consent was obtained from all individual participants included in the study.

\section{References}

1. Bronzoni RV, Moreli ML, Cruz AC, Figueiredo LT (2004) Multiplex nested PCR for Brazilian alphavirus diagnosis. Trans R Soc Trop Med Hyg 98:456-461

2. Cecilia D, Kakade M, Alagarasu K, Patil J, Salunke A, Parashar D, Shah PS (2015) Development of a multiplex real-time RTPCR assay for simultaneous detection of dengue and chikungunya viruses. Arch Virol 160:323-327

3. de Morais Bronzoni RV, Baleotti FG, Ribeiro Nogueira RM, Nunes M, Moraes Figueiredo LT (2005) Duplex reverse transcription-PCR followed by nested PCR assays for detection and identification of Brazilian alphaviruses and flaviviruses. J Clin Microbiol 43:696-702

4. Dutta SK, Pal T, Saha B, Mandal S, Tripathi A (2014) Copy number variation of Chikungunya ECSA virus with disease symptoms among Indian patients. J Med Virol 86:1386-1392

5. Figueiredo LT (2015) The recent arbovirus disease epidemic in Brazil. Rev Soc Bras Med Trop 48:233-234

6. Figueiredo LTM (1990) Uso de células de Aedes albopictus C6/ 36 na propagação e classificação de arbovírus das famílias Togaviridae, Flaviviridae, Bunyaviridae e Rhabdoviridae. Rev Soc Bras Med Trop 23:13-18

7. Gutierrez S, Thebaud G, Smith DR, Kenney JL, Weaver SC (2015) Demographics of natural oral infection of mosquitos by Venezuelan equine encephalitis virus. J Virol 89:4020-4022

8. Hueston L, Toi CS, Jeoffreys N, Sorrell T, Gilbert G (2013) Diagnosis of Barmah Forest virus infection by a nested real-time SYBR green RT-PCR assay. PLoS One 8:e65197 
9. Hull R, Nattanmai S, Kramer LD, Bernard KA, Tavakoli NP (2008) A duplex real-time reverse transcriptase polymerase chain reaction assay for the detection of St. Louis encephalitis and eastern equine encephalitis viruses. Diagn Microbiol Infect Dis 62:272-279

10. Kang X, Li Y, Liu H, Lin F, Cai X, Sun T, Chang G, Zhu Q, Yang Y (2010) A duplex real-time reverse transcriptase polymerase chain reaction assay for detecting western equine and eastern equine encephalitis viruses. Virol J 7:284

11. Katoh K, Standley DM (2013) MAFFT multiple sequence alignment software version 7: improvements in performance and usability. Mol Biol Evol 30:772-780

12. Levanov L, Kuivanen S, Matveev A, Swaminathan S, Jaaskelainen-Hakala A, Vapalahti O (2014) Diagnostic potential and antigenic properties of recombinant tick-borne encephalitis virus subviral particles expressed in mammalian cells from Semliki Forest virus replicons. J Clin Microbiol 52:814-822

13. Lundstrom K (2014) Alphavirus-based vaccines. Viruses 6:2392-2415

14. Mathijs E, Muylkens B, Mauroy A, Ziant D, Delwiche T, Thiry E (2010) Experimental evidence of recombination in murine noroviruses. J Gen Virol 91:2723-2733

15. Medina G, Garzaro DJ, Barrios M, Auguste AJ, Weaver SC, Pujol FH (2015) Genetic diversity of venezuelan alphaviruses and circulation of a venezuelan equine encephalitis virus subtype IAB Strain during an interepizootic period. Am J Trop Med Hyg 93:7-10

16. Mitsuhashi M (1996) Technical report: Part 2. Basic requirements for designing optimal PCR primers. J Clin Lab Anal 10:285-293

17. Morrison TE (2014) Reemergence of chikungunya virus. J Virol $88: 11644-11647$

18. Mourao MP, Bastos Mde S, de Figueiredo RP, Gimaque JB, Galusso Edos S, Kramer VM, de Oliveira CM, Naveca FG, Figueiredo LT (2012) Mayaro fever in the city of Manaus, Brazil, 2007-2008. Vector Borne Zoonotic Dis 12:42-46

19. Ni H, Yun NE, Zacks MA, Weaver SC, Tesh RB, da Rosa AP, Powers AM, Frolov I, Paessler S (2007) Recombinant alphaviruses are safe and useful serological diagnostic tools. Am J Trop Med Hyg 76:774-781

20. Nunes MR, Faria NR, de Vasconcelos JM, Golding N, Kraemer MU, de Oliveira LF, Azevedo Rdo S, da Silva DE, da Silva EV, da Silva SP, Carvalho VL, Coelho GE, Cruz AC, Rodrigues SG, Vianez JL Jr, Nunes BT, Cardoso JF, Tesh RB, Hay SI, Pybus OG, Vasconcelos PF (2015) Emergence and potential for spread of Chikungunya virus in Brazil. BMC Med 13:102

21. Perkins TA, Metcalf CJ, Grenfell BT, Tatem AJ (2015) Estimating drivers of autochthonous transmission of chikungunya virus in its invasion of the americas. PLoS Curr. doi:10.1371/ currents.outbreaks.a4c7b6ac10e0420b1788c9767946d1fc

22. Pfeffer M, Proebster B, Kinney RM, Kaaden OR (1997) Genusspecific detection of alphaviruses by a semi-nested reverse transcription-polymerase chain reaction. Am J Trop Med Hyg 57:709-718

23. Pisano MB, Oria G, Beskow G, Aguilar J, Konigheim B, Cacace ML, Aguirre L, Stein M, Contigiani MS (2013) Venezuelan equine encephalitis viruses (VEEV) in Argentina: serological evidence of human infection. PLoS Negl Trop Dis 7:e2551
24. Powers AM, Roehrig JT (2011) Alphaviruses. Methods Mol Biol 665:17-38

25. Reddy V, Ravi V, Desai A, Parida M, Powers AM, Johnson BW (2012) Utility of IgM ELISA, TaqMan real-time PCR, reverse transcription PCR, and RT-LAMP assay for the diagnosis of Chikungunya fever. J Med Virol 84:1771-1778

26. Sane J, Kurkela S, Levanov L, Nikkari S, Vaheri A, Vapalahti O (2012) Development and evaluation of a real-time RT-PCR assay for Sindbis virus detection. J Virol Methods 179:185-188

27. Santhosh SR, Parida MM, Dash PK, Pateriya A, Pattnaik B, Pradhan HK, Tripathi NK, Ambuj S, Gupta N, Saxena P, Lakshmana Rao PV (2007) Development and evaluation of SYBR Green I-based one-step real-time RT-PCR assay for detection and quantification of Chikungunya virus. J Clin Virol 39:188-193

28. Smith DR, Lee JS, Jahrling J, Kulesh DA, Turell MJ, Groebner JL, O'Guinn ML (2009) Development of field-based real-time reverse transcription-polymerase chain reaction assays for detection of Chikungunya and O'nyong-nyong viruses in mosquitoes. Am J Trop Med Hyg 81:679-684

29. Staples JE, Fischer M (2014) Chikungunya virus in the Americas-what a vectorborne pathogen can do. N Engl J Med 371:887-889

30. Strauss JH, Strauss EG (1994) The alphaviruses: gene expression, replication, and evolution. Microbiol Rev 58:491-562

31. Suhrbier A, Jaffar-Bandjee MC, Gasque P (2012) Arthritogenic alphaviruses-an overview. Nat Rev Rheumatol 8:420-429

32. Terzian AC, Auguste AJ, Vedovello D, Ferreira MU, da SilvaNunes M, Speranca MA, Suzuki RB, Juncansen C, Araujo JP Jr, Weaver SC, Nogueira ML (2015) Isolation and characterization of Mayaro virus from a human in Acre, Brazil. Am J Trop Med Hyg 92:401-404

33. Vaney MC, Duquerroy S, Rey FA (2013) Alphavirus structure: activation for entry at the target cell surface. Curr Opin Virol 3:151-158

34. Vieira CJ, Silva DJ, Barreto ES, Siqueira CE, Colombo TE, Ozanic K, Schmidt DJ, Drumond BP, Mondini A, Nogueira ML, Bronzoni RV (2015) Detection of Mayaro virus infections during a dengue outbreak in Mato Grosso, Brazil. Acta Trop 147:12-16

35. Vieira MA, Romano AP, Borba AS, Silva EV, Chiang JO, Eulalio KD, Azevedo RS, Rodrigues SG, Almeida-Neto WS, Vasconcelos PF (2015) West Nile virus encephalitis: the first human case recorded in Brazil. Am J Trop Med Hyg 93:377-379

36. Weaver SC, Winegar R, Manger ID, Forrester NL (2012) Alphaviruses: population genetics and determinants of emergence. Antiviral Res 94:242-257

37. Yang CF, Chen CF, Su CL, Teng HJ, Lu LC, Lin C, Wang CY, Shu PY, Huang JH, Wu HS (2010) Screening of mosquitoes using SYBR Green I-based real-time RT-PCR with group-specific primers for detection of Flaviviruses and Alphaviruses in Taiwan. J Virol Methods 168:147-151

38. Zacks MA, Paessler S (2010) Encephalitic alphaviruses. Vet Microbiol 140:281-286

39. Zink SD, Jones SA, Maffei JG, Kramer LD (2013) Quadraplex qRT-PCR assay for the simultaneous detection of Eastern equine encephalitis virus and West Nile virus. Diagn Microbiol Infect Dis $77: 129-132$ 